\title{
Review Paper on Applications and Techniques in Concrete Printing
}

\author{
B. Ritish Reddy ${ }^{1}$, J. Rakesh ${ }^{2}$, B. Varun ${ }^{3}$, B. Rakesh Kumar ${ }^{4}$, Asst. Prof G. Lalitha ${ }^{5}$ \\ 1,2,3,4,Dept. of Civil Engineering, VNR Vignana Jyothi Institute of Engineering \&Technology, Telangana, India \\ 5Asst prof Dept. of Civil Engineering, VNR Vignana Jyothi Institute of Engineering \&Technology, Telangana, India
}

\begin{abstract}
D concrete printing is an emerging technique in construction field. 3D printing mainly focused on reduction of formwork, utilization of time and using the materials ecofriendly. 3D printing is mainly divided into two techniques where contour crafting may revolutionize construction industry in near future. These technologies could create a new era of architecture that is better adapted to the environment and integrated with engineering function. Despite of many advantages, the limitations of this technology is also summarized in conclusion.
\end{abstract}

Keywords: 3D printing of concrete, formwork, motor, STL file format, and computer aided design, contour crafting, and construction digital construction.

\section{INTRODUCTION}

We know that the construction industry almost runs with concrete. From a recent study, form work is responsible for $80 \%$ of the total construction cost of concrete. Disadvantages of following conventional construction methods are: formwork, time consuming, more waste generated and labour safety while doing work, huge amounts of greenhouse gases evolved. 3D concrete printing could solve many drawbacks in conventional method of construction. It is recently gaining popularity in construction industry. 3D printing, also known as additive manufacturing (AM), is a group of emerging techniques for fabricating 3D structures directly with a software in successive layers with less waste material. Initially AM technologies were developed in the 1980s. Currently, AM technologies become the main source of modern product Development and successfully applied in a wide range of sectors including aerospace and automotive manufacturing, biomedical, consumer and food.

\section{LITERATURE REVIEW}

\subsection{Izabela Hager, et al. (2016)}

They have studied regarding the history and an overview about the concrete printing technology. And also they mentioned some case studies regarding the application of this technology. In1983, Charles.W introduced the first 3D concrete printing technology. He used STL (stereo lithography) technology for this. Then later, another technology named as FDM (Fused deposition modelling) was introduced by S.Scott crump in 1988. The first case study was in 2014, Dutch architects built a house using concrete printing. They built the house with individual components. It took around 3 months for construction. The second case study was Winsum Company built a model house using their own software. Then later, they built a 5 storey building using concrete printing with the same software. And the building was the tallest construction with concrete printing technology till now in the world.

\subsection{Antony Thorpe, et al. (May, 2014)}

They developed a concrete printing machine using additive manufacturing (AM) technology. They printed a Wonder bench using concrete printing technology. First they designed a 3D cad model for the bench, later it was converted into STL (stereo lithography) format. Then printing path was generated. After that they developed a Gcode for printing process, then printing of bench was done. In this project, they used a concrete made with both cement and gypsum materials. The concrete density was $2400 \mathrm{~kg} /$ cubic meters. The concrete was 3 times stronger in compression and flexure when compared with normal concrete. The strength of this concrete was found around $100-110 \mathrm{mpa}$. In this project they used $9 \mathrm{~mm}$ nozzle for printing operation. And it prints $1.4 \mathrm{~kg} /$ minute. The bench height was $0.8 \mathrm{~m}$ and it weighs 1 tonne. They provided functional voids in bench construction and later they post tensioned the voids such that the bench would be strong in tension also.

\subsection{Byung Wan Jo, et al. (2020)}

They printed a hollow concrete wall using 3D concrete printing technology. First they developed a prototype model for checking its performance before developing full size model. Using that prototype, they printed the wall. The prototype model was $1 \mathrm{Mx} 1 \mathrm{Mx} 1 \mathrm{M}$ in dimensions. The study was mainly focused with 3 targets. 1) 3D space motion control.2) Properties of concrete material.3) Material dispensing process. In motion control, they used FDM technology with help of software which they personally developed. In material properties, they used conventional concrete with a small size of aggregates. In the dispensing process, they used a screw type nozzle for the extrusion process. The diameter of the nozzle is $50 \mathrm{~mm}$. They did a compressive strength test on printed models on different mix designs. And it's average compressive strength is obtained around 61Mpa.

\subsection{Van Der Putten, et al. (July 2020)}

They conducted an experiment on printed samples to test the levels of chloride penetration in it and compared it with the one which is built using conventional construction method. They found that there is more shrinkage, internal voids and crack formation, increases the amount of preferential penetration path for chemical substances when followed this technique. The penetration of chloride in moulded specimens is uniform all over the entire sample 
height and the same conclusion can be made for printed specimens fabricated with a zero minute time gap. As the inter layer time interval increases, the amount of chloride ingress also increases.

\subsection{Imane Krimi, et al. (June 2017)}

They demonstrated about two key parameters to evaluate the printability of binding materials like cement. The key parameters are: Extrudability and Buildability. Four mixes were tested to determine their extrudability and buildability. Extrusion was influenced by sand granular distribution. In this study 'SLI' sand has a spread granular distribution while BB sand has a tight granulometry. Buildability expresses the early age resistance of the material. It is strongly correlated to the yield stress. The properties presented in this paper were used to define a printable mix design through different iterations. This mix was then tested in a large scale $3 \mathrm{D}$ printer, no clogging was recorded.

\subsection{Rabab Allouzi, et al. (April 2019)}

This paper proposes the use of nanotechnology in real structural engineering projects with the 3D printing construction procedure. They suggested the use of graphene nanomaterial for 3D printing of concrete structures. Recently, it is getting more attention due to its remarkable properties including its tensile stress of $130 \mathrm{GPa}$ at strain of 0.25 and Young's modulus of 1TPa. While traditional types of concrete is not convenient for 3D printing and due to the extraordinary properties including its tensile strength, compressive strength, and Young's modulus, this paper suggests the use of treated graphene oxide as nanomaterial for $3 \mathrm{D}$ printing of Concrete structures

\subsection{Manju.R, et al. (August 2019)}

They have studied on the process of additive manufacturing (AM) and explained the detail procedure of working of 3D printers where they use g-codes. Here, for the machine the $\mathrm{x}, \mathrm{y}$ and $\mathrm{z}$ coordinates are given and the printer is connected with a robotic arm setup and nozzle across printers. Also gave the details about softwares for slicing which were the details required by the printers. Mentioned about the stepwise process of 3D printing which the structure was built under the given program . Took some case studies regarding 3D printing around the world. Finally they concluded by giving an idea about the future scope of 3D printing.

\subsection{Behzad Nematollahi, et al. (2017)}

They mainly focused on the techniques through which 3D printing is done and categorised as extrusion-based technique and powder-based technique and further classified both regarding those techniques among them under extrusion-based technique, concrete printing was mentioned where the made a bench of length $2 \mathrm{~m}$, width $0.9 \mathrm{~m}$ and a height of $0.8 \mathrm{~m}$ which comprised of 128 layers with $6 \mathrm{~mm}$ thickness which included 12 voids. Under powder-based technique, powder-based 3DCP using geopolymer was mentioned where they analysed the strength of structure regarding its orientation. They found that orientation by $\mathrm{X}$-axis had $20 \%$ green strength more than in orientation by $\mathrm{Z}$-axis. Also the percentage change between the strength in orientation by $\mathrm{X}$-axis and orientation by $\mathrm{Z}$-axis was decreased to $12 \%$ and $5 \%$ for 1 and 7-days post-cured samples, respectively and finalised that post-curing procedure in $3 \mathrm{D}$ printed geopolymer structures reduces the anisotropic phenomenon.

\subsection{Yasmin Tarhan, et al. (April 2019)}

They started up with the detailed explanation from CAD file to $3 \mathrm{D}$ printed object and collected information about $3 \mathrm{D}$ printers about where they started and the evolution of $3 \mathrm{D}$ printers till date. They researched on the properties of the concrete mix used for 3D printing and explained about the properties which were extrudability, workability, open time which should be enough to maintain extrudability, contact strength between layers, aggregates, water-cement ratio with at least of 0.25 and buildability. Also explained about the present challenges and opportunities which the world of construction overcome the limitations of the past and found new technology for large scale development. Finally they concluded with some solutions to make 3D concrete more efficient.

\subsection{Amitkumar D. Raval, et al. (March 2020)}

They discussed the risks and challenges, even having many benefits of this technology as the technology is in the initial stage and has many limitations. Environmental concerns are also discussed in the paper. They demonstrated many processes involved in concrete printing. Formulating computer models plays a crucial role in implementation of this technology. Development in 3D computer graphics makes it possible to fabricate such digital models easily using commercially available as well as open-source software packages. They concluded that he investigation required in the printing technique includes selection new nozzle with optimum size and shape, a novel method of extrusion and also a new method of delivery that enhance the overall quality of the printing.

\subsection{Guowei, et al. (April 2017)}

They mainly focused their work on studying current methodologies of printing technology and evaluated methods for materials feasible for concrete printing. They started up with the explanation of three large scale 3D printing systems which have been successfully implemented in the construction industry. They also summarised the commonly used raw materials and the measures to be taken to get the critical requirements of freeform construction process. Measuring methods to determine the fresh and hardened properties of concrete at early stage were also suggested. The concrete mixture must be easy-flowable and easy-extrudable, aggregate and coarse sand must be eliminated during the preparation.

\subsection{Victor Molodin, et al. (April 2020)}

They experimented upon the use of single-stage polystyrene concrete as the material for fabricating objects using concrete printing technology .They found that even 
in case of complex builded structures, the labour consumption of formwork is far less than $40 \%$ and 3D printers will take only this small amount of work. A wall printed using polystyrene concrete has a vast number of advantages and it also helps us to ensure the uniform distribution of polystyrene granules over the whole wall material which in turn increases the high quality thermal resistance and ensures the specified strength characteristics of the erected wall.

\section{CONCLUSION}

Usage of 3D printing concrete technology is an upcoming technology in future. The literature discussed in the present paper has given an overview of the basic process involved in this technology and the application of this technology. This 3D concrete printing technology has a wide range of advantages like Time efficiency, Freedom of building any geometrical design, environmentally friendly construction, Economy etc. Although it has disadvantages like Accuracy in the work need skilled labour etc. But now-a- days there will be some ambiguity in strength and performance of this technology. Here we are concluding that this is a secured construction technology and we all need to accept this technology in the construction field.

\section{REFERENCE:}

[1] Izabela Hager, el at. Cracow University of Technology, Warszawska str.24, Cracow, Poland. International Conference on ecology and new building materials and Products, (ICEBMP). DOI: 2016

[2] Sungwoo Lim, el at. Department of civil \& building engineering, Loughborough University, UK DOI: May 2014.

[3] Byung Wan Jo, el at. Department of Civil and Environmental Engineering, Hanyang University, Republic of Korea. DOI: 2020

[4] J. Van der putten, el at. Van tittelboom Mangel-vandepitte laboratory for Structural Engineering and Building Materials, Ghent University, Belgium. DOI: July 2020

[5] Imane Krimi, el at. Bouygues construction, Avenue De Horizon, Haute Borne. DOI: June 2017

[6] Rabab Allouzi, Assistant professor of civil Engineering, the university of Jordan, Amman, Jordan. DOI: April, 2019

[7] Manju R, et al. DOI: August 2019

[8] Bezhad Nematollahia, et al. Center for Sustainable Infrastructure, Swinburne University of Technology, Melbourne, Australia. DOI: 2017

[9] Yesim Tarhan, et al. Department of Civil Engineering, Ataturk University, Turkey. DOI: April 2019

[10] Amitkumar D.Raval, Ganpat university, Gujrat, Head of the Civil engineering department, U.V. Patel Engineering college, Ganpat university, Gujrat. DOI: March 2020

[11] Guowei, el at. College of Architecture and Civil Engineering, Beijing University of Technology, Beijing, China. DOI: April 2017

[12] Victor Molodim, el at. Head of the Department of Construction Technology and Organization, Russian Federation. DOI: April 2020 